\title{
Chromosomes of the Puerto Rican "vaquita," Diaprepes abbreviatus (L.) (Curculionidae: Otiorrhynchinae: Phyllobiini) ${ }^{1}$
}

\author{
Niilo Virkki² and Julia M. Seprilveda"
}

\begin{abstract}
Diaprepes abbreviatus has typical chromosomes of the bisexual weevils of the subfamily Otiorrhynchinae: $2 n=22 ; 2 X(q) ; 2 n=22 ; X, y(\delta)$, the male meioformula being $10+X y_{p}$. The autosomes form an evenly-diminishing series of near-mediocentrics. Some speculations are presented regarding how a meiotic drive, suitable for control purposes, might be established in such a trivial karyotype.
\end{abstract}

\section{RESUMEN}

Los cromosomas de Diaprepes abbreviatus

La vaquita, Diaprepes abbreviatus, tiene cromosomas típicos de los picudos bisexuales de la subfamilia Otiorrhynchinae: $2 n=22 ; 2 X(9) ; 2 n$ $=22 ; \mathrm{X}, \mathrm{y}(\hat{\jmath})$. La meiofórmula del macho es $10+X y_{\mathrm{p}}$. Los autosomas forman una serie de tamaños que varia gradualmente de más grandes a más pequeños. Se presenta un plan cómo un mecanismo meiótico (meiotic drive) podria utilizarse en el control de la vaquita.

\section{INTRODUCTION}

The phyllobiine weevil Diaprepes abbreviatus is an injurious and ecologically versatile pest insect of Puerto Rican agriculture and silviculture. Its hosts comprise at least 70 species of wild and cultivated plants (8). It occupies the entire island. The larvae, sheltered in the host roots, are perhaps more injurious than the adults. Despite native and introduced enemies $(4,29)$, this ecological versatility of the vaquita has prevented its effective control.

Original studies on genetics and cytology of the vaquita in Puerto Rico were begun in 1982. We now visualize its population as a continuous "carpet" of interbreeding demes covering the entire island. The population is locally modified by discrete color (6) and chiasma-frequency (11) patterns. Wolcott (29) suggested parasitism as a factor of color variation, but we suspect genetic causes. The host plant probably does not affect this variation, but geographic origin does.

Four principal elytron color regions can be distinguished:

1. Western lowlands: Whitish background, often with a yellow side strip on each elytron.

'Manuscript submitted to Editorial Board 4 October 1989.

${ }^{2}$ Cytogeneticist, Department of Crop Protection.

${ }^{3}$ Laboratory Assistant, Department of Crop Protection. 
2. Cordillera Central: Background white, yellow, or golden brown, with one extra full-length vitta per elytron, and yellow or red side strips (6).

3. Eastem lowlands: Brown background, a yellowish periscutellar spot or area in the south, a grayish one in the north. No distinct side strips.

4. El Yunque, middle and higher elevations: Background whitish, often tinted pink or metallic green. No distinct side strips.

The lowland color morphs meet somewhere between Dorado and Manati in the north, and in the Ponce region in the south.

Because the color patterns cannot be explained by direct selection, they are presently interpreted as non-sensical variations due to pleiotropy, or to close linkage of their genes with more important genes under selection. We could not identify such genes in electrophoretic studies. Only the El Yunque deme bore significant genetic distinctions from the others (6).

Approximately a thousand specimens from different Puerto Rican localities have been examined cytologically since 1982. Chromosomal variation appeared virtually nil. The minimal variation found will be described in this paper. Chromosome number and morphology of bisexual Otiorrhynchinae do not appear to be supportive of taxonomic and phylogenetic studies. Almost all diploid Otiorrhynchinae have had $2 \mathrm{n}=$ 22 ; $\mathrm{X}, \mathrm{y}$; the male meioformula being $10+\mathrm{Xy}_{\mathrm{p}}(15,21)$. Even the polyploid series found frequently in parthenogenetic Otiorrhynchinae (16) are based on the haploid number 11 .

A detailed account of the chromosome relationships of such a cytologically trivial species might ordinarily seem superfluous. Its current significance stems from the extraordinary economic importance of vaquita. Moreover, this account is supportive of possible future attempts at genetic engineering of this weevil.

\section{MATERIAL AND METHODS}

Samples of vaquita were collected from 1982 to 1989, from woody and herbaceous host plants in Puerto Rico and the adjacent islands of Mona, Culebra and Vieques. Beetles were brought to the laboratory chilled at $20^{\circ} \mathrm{C}$ in an iced container. For male meiosis, testes were dissected out, fixed in KS (Kahle-Smith) fixative for one minute, or in acetic ethanol (1:3) for 2 hours. Sometimes, a hypotonic pretreatment in $0.075 \mathrm{M} \mathrm{KCl}$ or distilled water was applied. The testes were squashed on albuminized slides (24) and examined immediately by phase contrast microscopy. Selected preparations were processed further for silver staining in accordance with Pathak and Elder (9), by conventional Giemsa and Feulgen methods, or by acetocarmine. 
For embryonal mitoses, females were maintained in plastic cages where strips of thin waxy paper were available for oviposition. The vaquita lays eggs between two such strips that subsequently remain attached. Separation of the strips usually leaves the egg group attached to one or the other. Such exposed egg groups, 2 days old or older, with some of the surrounding paper, were attached with tape onto the bottom of a small petri dish and covered with $0.01 \%$ to $0.2 \%$ colchicine prepared in Ringer solution. Under a stereomicroscope, the eggs were punctured with sharpened insect pins, and left for 1 to 6 hours in the solution. Thereafter, the colchicine solution was replaced with acetic ethanol (1:3), and the sample allowed to stand for 1 to 4 hours at room temperature, with at least two changes of the fixative. Sometimes, a short $(30 \mathrm{sec})$ refixation in KS was performed to toughen the tissue. Stains and occasional hypotony were applied as described above.

Fragments of fixed embryon were squeezed out of the egg in a drop of $45 \%$ acetic acid on an albuminized slide. The fragments were teased with insect pins in very small pieces and spread on a surface of about 18 $\times 18 \mathrm{~mm}$. Such a pre-squash distribution avoids formation of large metaphase groups where all chromosomes are mixed together. Using a cover slip of $22 \times 22 \mathrm{~mm}$ and moderate pressure, we obtained a sufficient number of solitary metaphases, revealing the correct chromosome number. Some preparations were C-banded in accordance with Vidal and Giacomozzi (22).

A Zeiss Photomicroscope II and Kodak Plus-X Pan Film ${ }^{4}$ were used for observations and photography. Selected mitosis negatives were blown to high magnification positives in a Durst enlarger. The chromosomes were cut out and arranged to karyograms of decreasing size order, from left to right, with sex chromosomes to the right. After rephotographing, karyogram magnification was adjusted to about $800 \mathrm{x}$.

\section{RESULTS}

The karyograms

Colchicinized chromosomes (fig. 1, A, and C) are more compact than hypotonized ones (Fig. 1, B) and reveal more or less flared chromatids, helping to determine the position of centromeres. Condensation of chromosomes under influence of colchicine may proceed differentially in eu- and heterochromatin. This is the case with the so-called diphasic chromosomes of Coleoptera $(14,15,25)$. Diphasism was not encountered in the vaquita chromosomes. Thus, the arm proportions should remain

\footnotetext{
Trade names in this publication are used only to provide specific information. Mention of a trade name does not constitute a warranty of equipment or materials by the Agricultural Experiment Station of the University of Puerto Rico, nor is this mention a statement of preference over other equipment or materials.
} 


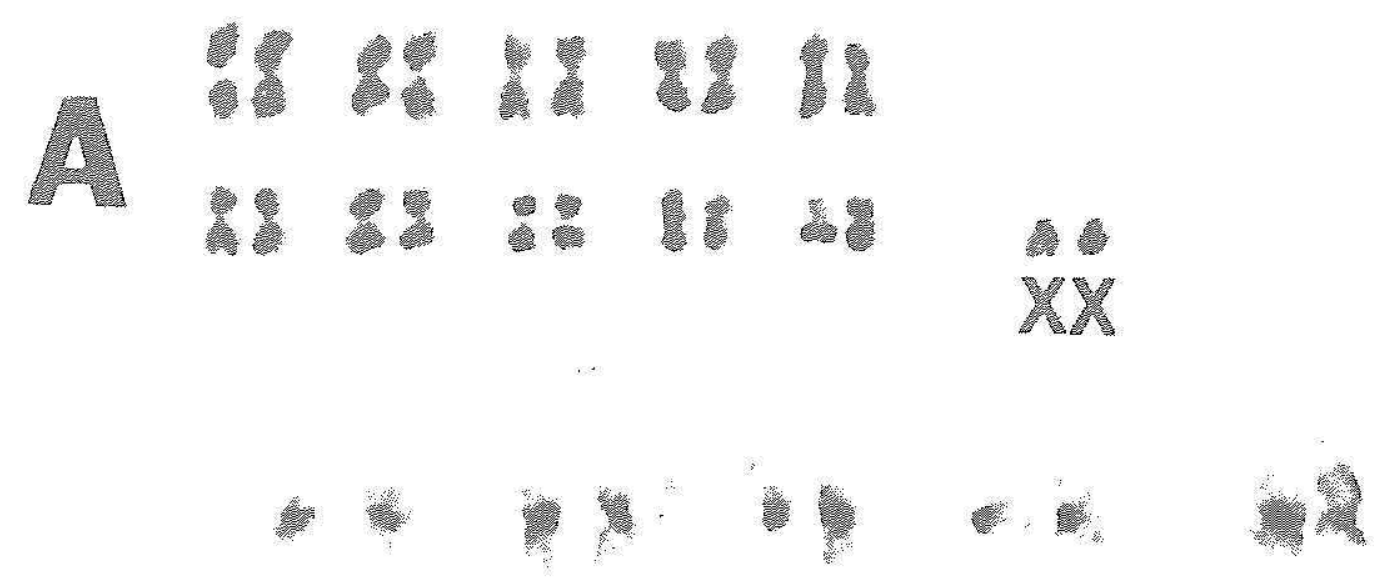

8

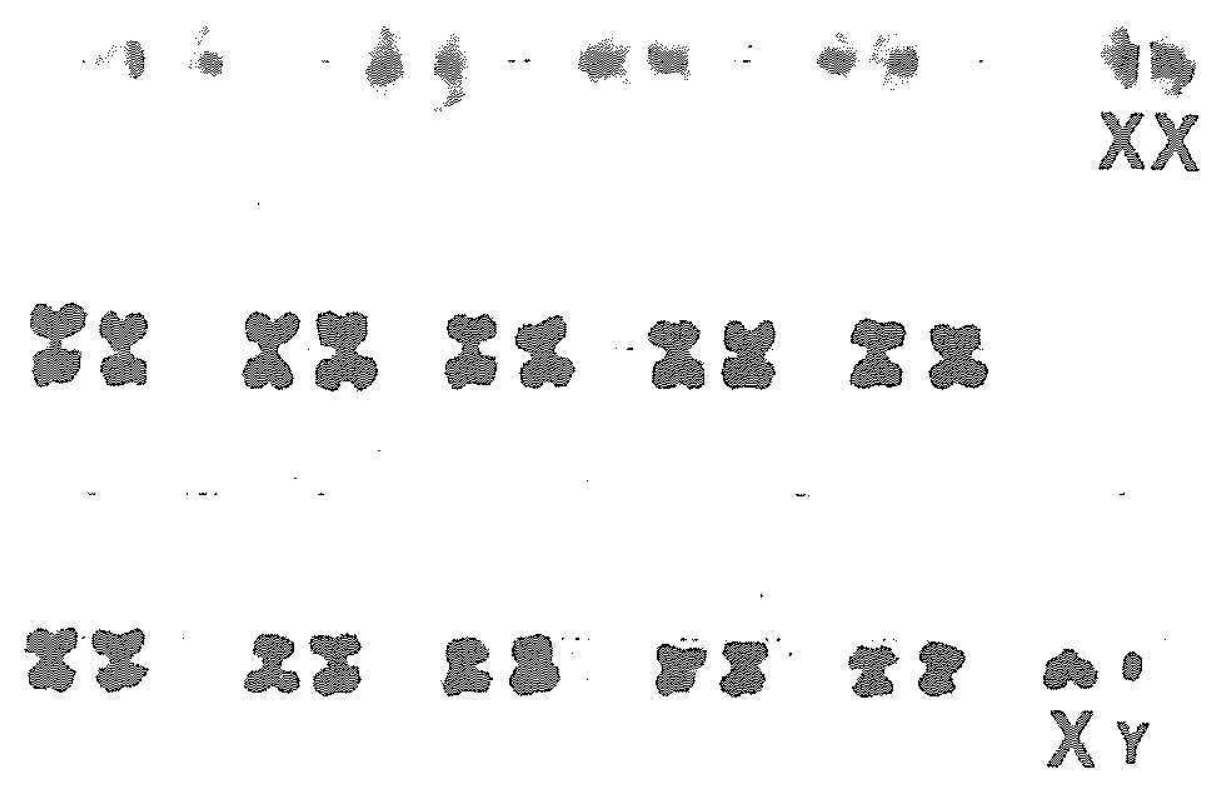

FIG. 1.-A to C. Karyograms of Diaprepes abbreviatus from Puerto Rico. $2 \mathrm{n}=22(2 \mathrm{X})$ in female, $=22(X, y)$ in male. A. $0.02 \%$ colchicine for $30 \mathrm{~min} .-\mathrm{KS}+$ Phase contrast. From a female embryon of 5 days. Origin unknown. B. $0.075 \% \mathrm{KCl}$ for $30 \mathrm{~min}$. $-\mathrm{KS}+\mathrm{AgNOR}$. From a female embryon of 3 days. Origin: Isabela. C. $-0.2 \%$ colchicine for $1 \mathrm{~h}-\mathrm{KS}+\mathrm{Phase}$ contrast. From a male embryon of 3 days. Origin: El Yunque, Catalina.

unchanged. The absolute length of the chromosomes is proportional to the nuclear size, and therefore some length variation was to be expected because of the various unidentified embryonal tissue sources.

The 10 autosomes of vaquita are difficult to distinguish from one another. All tend to appear mediocentric and form an evenly-diminishing: array, with the proportion $\begin{aligned} & \text { longrst } \\ & \text { shortest }\end{aligned}$ being about 1.8 (fig. 1). The X chromo- 
some is acrocentric and ordinarily appears slightly shorter than the shortest autosome. The tiny y chromosome may appear punctiform or slightly lengthy, probably being a metacentric of very uneven arms (fig. 2, A).

AgNOR staining (fig. 1, B) reveals conspicuous and very similar argyrophilic segments in the procentric region of all chromosomes. The resultant appearance is nearly identical with C-banding $(1,5,12,13,24,26$; not shown here). The procentric argyrophily just might indicate condensation; the argyrophilous points are closer together in the compact heterochromatin than in euchromatin.

According to these karyograms, the diploid chromosome number of Diaprepes abbreviatus is $2 n=22 ; 2 \mathrm{X}$ (female), and $2 \mathrm{n}=22$; $\mathrm{X}, \mathrm{y}$ (male). Both numerically and morphologically the chromosomes are typically Otiorrhychinean.

\section{Spermatogenesis}

Spermatogonia (fig. 2) indicate $2 \mathrm{n}=22 ; \mathrm{X}, \mathrm{y}$, consistent with the embryonal mitoses. The y chromosome appears punctiform or slightly elongated, with one end more compact than the other (fig. 2, A). Prolonged hypotony flares chromatids of all autosomes, but minimally affects the sex chromosomes (fig. 2, B).

Pachytene bouquets show positively heteropycnotic knobs corresponding to the procentric heterochromatin (figs. $3, \mathrm{~A}$ to $\mathrm{C}$ ). There should
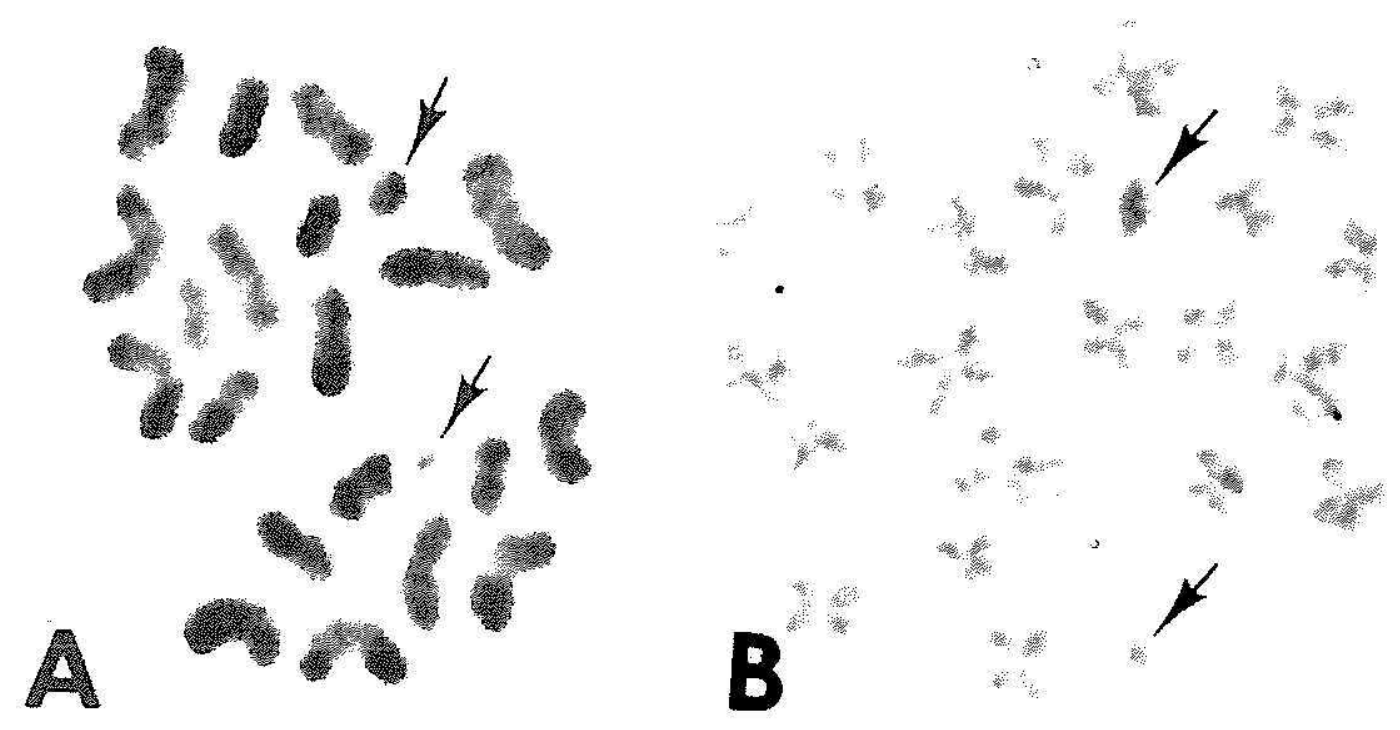

FrG. 2.-A and B. - Spermatogonial metaphases. Sex chromosomes shown by arrows $X>y$ ). A. - KS + Phase contrast, from a specimen found in 22.VI.85 on Croton sp. in (Culebra. B. - Aq. dest. $30 \mathrm{~min}$. + KS + Phase contrast, from a specimen taken in 31.VIII.88 from bigleaf mahogany in Catalina, El Yunque. Note how the chromaticts of all autosomes are flared, revealing the exact site of centromere. $X$ chromosome resists hypotony better than the autosomes. - A $1556 \mathrm{x} ; \mathrm{B} 1766 \mathrm{x}$. 


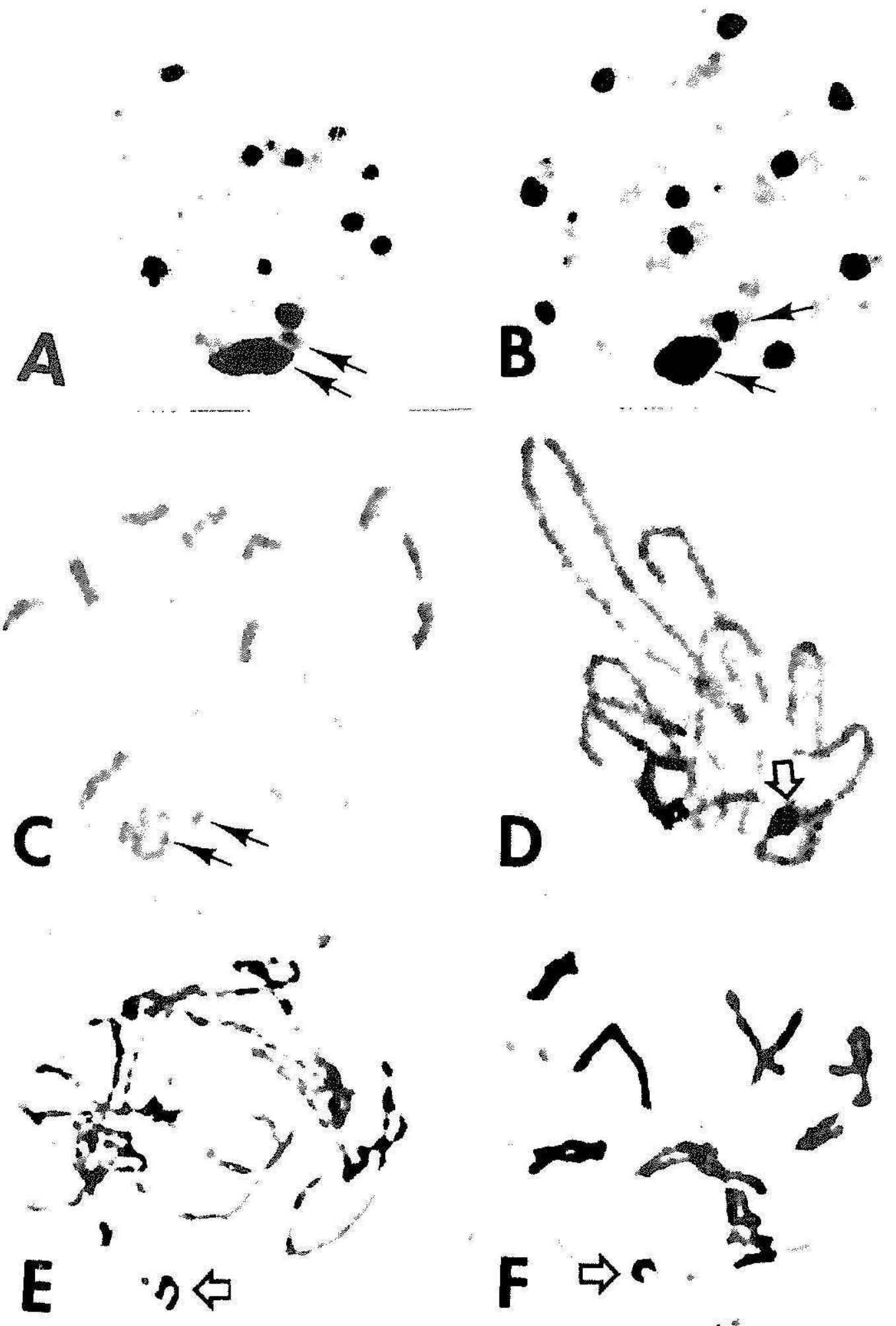

FIG. 3.-A to F. - Prophase of spermatocyte I. Sex chromosomes shown by arrows, sex bivalent, by hollow arrow. A. - KS + AgNOR, from a specimen taken in 13.VII.83 from pigeon pea in Culebra. Pacytene bouquet showing faintly stained autosomal loops with heavily stained procentric heterochromites, as well as heteropycnotic $X$ and $y . B$. - As in 
be 10 of them, but 11 are often seen. The eleventh one is the y chromosome, in close proximity to the $\mathrm{X}$ chromosome, although not joining it by any clearly recognizable link. More common are diffuse pachytenes, nuclei where the autosomal loops are not more recognizable but the location of the sex chromosomes and procentric heterochromites suggests presence of bouquet organization (figs. 2, B and C). In nuclei far advanced towards diffusion, the autosomal heterochromites have a decondensed, lengthy appearance, whereas the sex chromosomes seem to have lost not only compactness but also material adjacent to them (fig. $3, \mathrm{~B}$ vs. 3, C). Staining and extraction experiments suggest that the material is nucleolar in nature (28). In lack of active nucleolus organizer, it soon disintegrates and disappears.

When the euchromatin condenses, the procentric regions appear isopycnotic, at times even negatively heteropycnotic, as compared to euchromatin (fig. $3, \mathrm{D}$ ). The bouquet organization yields to a diplotenicdiakinetic organization (fig. $3, \mathrm{E}$ and $\mathrm{F}$ ) where the bivalents relocate to the periphery of the nuclear space. In these early phases, the sex bivalent resembles a question mark in form. The $\mathrm{X}$ chromosome is curved to form a loop, with the y chromosome visibly connected with one of the loop ends. This configuration does not essentially differ from the end-to-end associated sex chromosomes of the very early prophase (27).

A specimen from El Yunque (Catalina) shows frequent association of one autosome with the sex bivalent, two double minutes being also present (fig. 4).

The first meiotic metaphase shows 10 autosomal bivalents plus a parachute-shaped sex bivalent, $\mathrm{Xy}_{\mathrm{p}}$ (fig. 5, A). Both ends of the $\mathrm{y}$ chromosome are joined with the ends of the $\mathrm{X}$ chromosome. The space between $\mathrm{X}$ and $\mathrm{y}$ can appear empty under phase contrast, and with most stains (28), but stains heavily with the AgNOR techniques, especially if formalin-containing fixative is used. The substance thus marked is not nucleolar (27). The 10 autosomal bivalents can be unichiasmate dumbbells, as in fig. 5 , A, although up to six bibrachially-bichiasmate rings have been seen (11).

\section{$\longleftrightarrow$ \&IIIK}

A, but an older bouquet approximating diffuse stage. C. - KS + Phase contrast, from a specimen taken from bigleaf mahogany in 1.VIII.86 in Catalina, El Yunque. Diffuse bouquet. Note decondensation of all heteropycnotic elements, and obvious loss of substance from the sex chromosomes. D. - KS + Giemsa, from a specimen found on mango in Rio Piedras in November, 1985. Post-diffuse bouquet. Note how condensation of euchromatin incorporates the procentric heterochromites, which may now show even gaps (the longest loop). E. - KS + Acetocarmine, from a specimen taken from bigleaf mahogany in 16.IX.86 in Catalina, El Yunque. Young diplotene. F, - Same specimen and preparation as in E. Diplotene. Note the questionmark shape of Xy bivalent in these diplotene cells. - A to C $2225 \mathrm{x} ; \mathrm{D} 1766 \mathrm{x} ; \mathrm{E}$ and F $1835 \mathrm{x}$. 


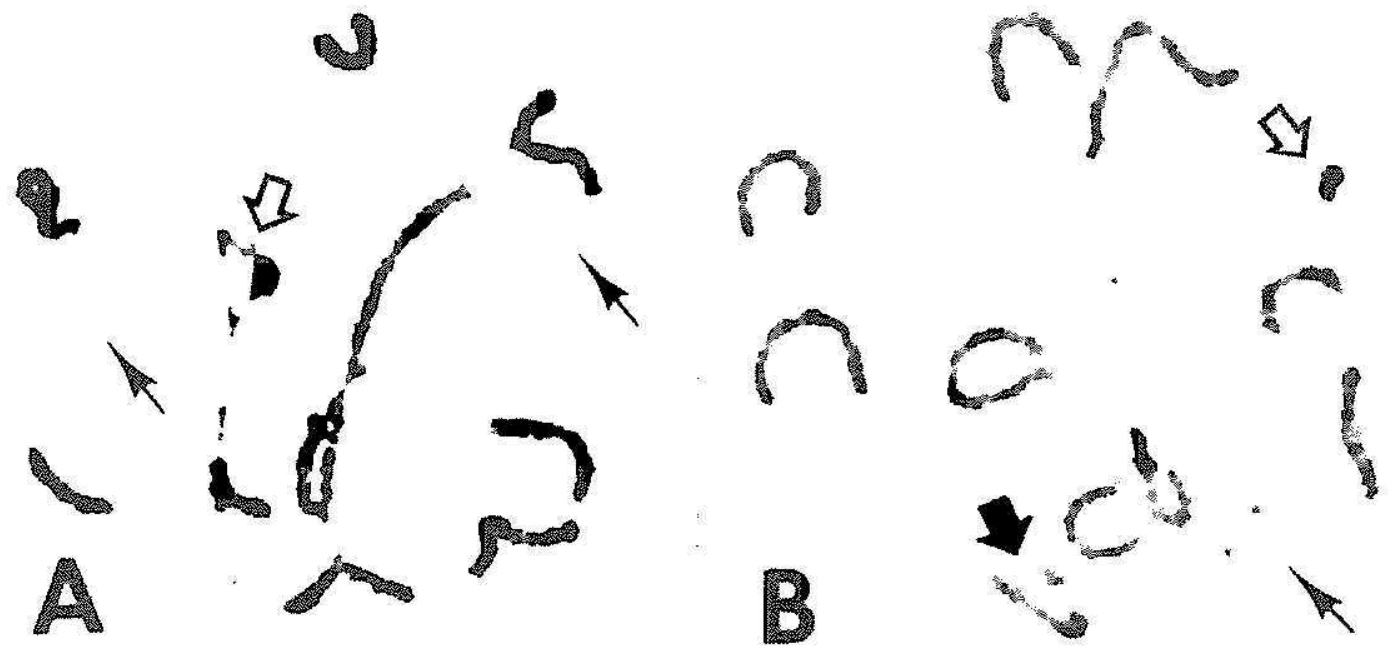

FrG. 4.-A and B. Translocation and minute supernumerary chromosomes in diplotene nuclei of a specimen found on bigleaf mahogany in 15.X.87 in Catalina, El Yunque. KS + $1 \mathrm{~h}$ acid hydrolysis + acetocarmine + AgNOR. A. - Hollow arrow points to a translocate where the short chromosome of heteromorphous bivalent has joined with an euchromatic segment of $\mathrm{X}$ chromosome. Thin arrows show faintly stained minutes. B. - Thick arrow points to the heteromorphous bivalent which has no contact with the sex bivalent, shown by a hollow arrow. $-1835 \mathrm{x}$.

In the first anaphase, the bivalents break down to two haploid sets of chromosomes (fig. 5, B). As is to be expected, plates of second metaphase disclose eleven chromosomes, either X or y among them (fig. 5, C). The $\mathrm{X}$ chromosome is positively heteropyenotic and thus argyrophilous at the telophase of the first division (figs. 5, D).

\section{DISCUSSION}

The karyotype

Chromosome number and meioformula of all Puerto Rican Phyllobiini are the same: $2 \mathrm{n}=22 ; 2 \mathrm{X}$ (female); $2 \mathrm{n}=22 ; \mathrm{X}$, y; with meioformula 10 $+\mathrm{Xy}_{\mathrm{p}}$ (male). Their karyotypes are also very similar (Virkki, unpubl.). Although karyograms of Phyllobiini studied elsewhere are not available for comparison, most illustrations of the mitotic and meiotic chromosomes of bisexual Otiorrhynchinae indicate the same $2 \mathrm{n}$ number, and very similar chromosomal morphology (lit. in 15,19,21).

Increase of the autosomal number by one pair has been reported in two Japanese Phyllobiini, Phyllobius longicornis Roelofs $(17,19,20)$ and $P$. rotundicollis Roelofs (18). The extra pair is small in the former species and large in the latter. Because intermediate numbers were not encountered in localities where both species occur, sibling species might be involved and should be sought by means of other taxonomic criteria.

Temporary association of one autosomal bivalent with $\mathrm{Xy}_{\mathrm{p}}$ has been repeatedly observed in Coleoptra, for instance in Pleocoma 


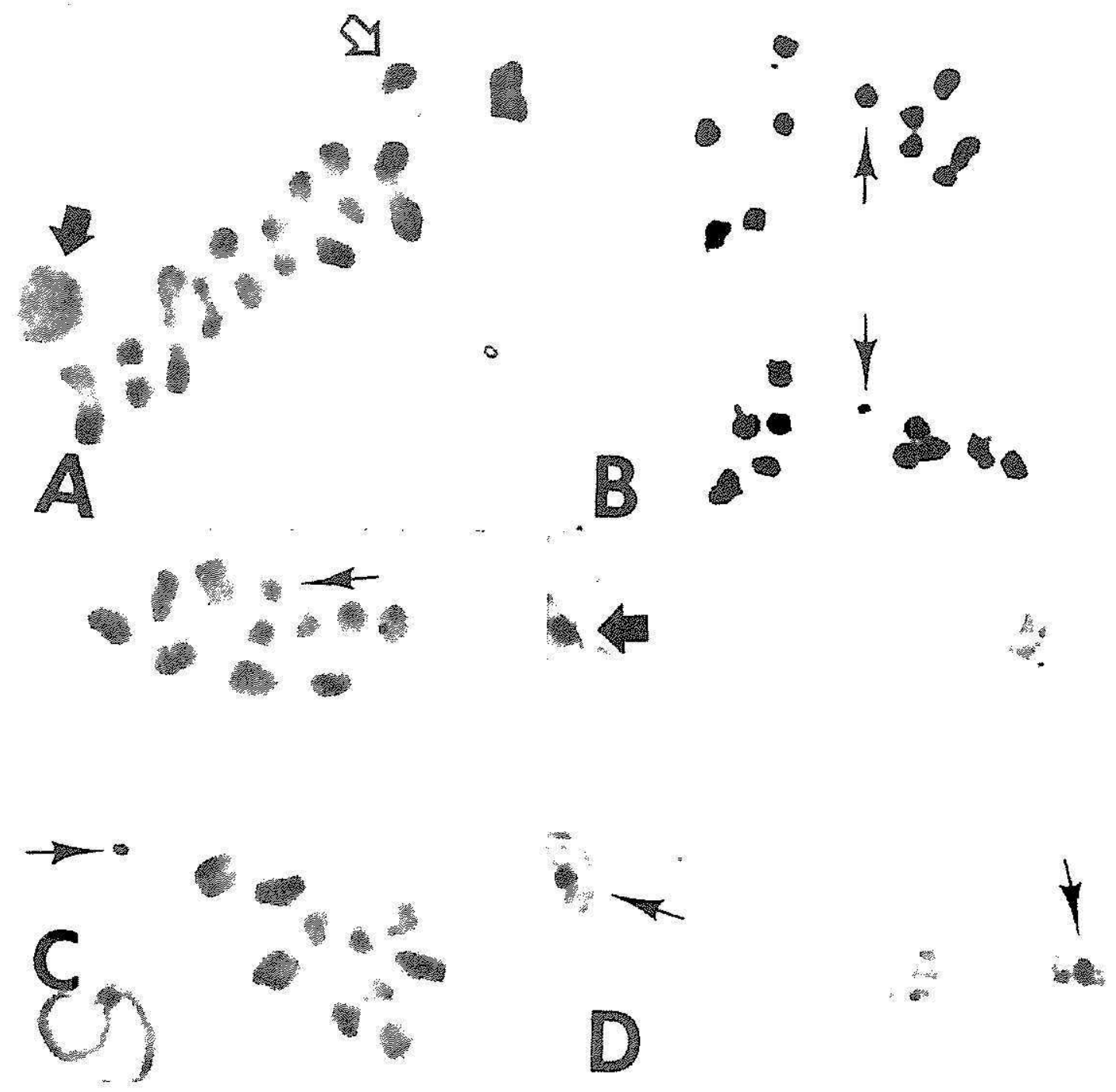

FIG. 5.-A to D. - Meiotic divisions of male. All illustrations are from specimens found on bigleaf mahogany in Catalina, El Yunque, in 1988-89. A. - KS + Phase contrast. M I: $10+\mathrm{Xy}_{\mathrm{p}}$. Hollow arrow points to $\mathrm{Xy}_{\mathrm{p}}$, filled arrow to an inessential body (spermatid nucleus). B. $-\mathrm{KS}+\mathrm{AgNOR}$. A I; segregation in $10+\mathrm{X} / 10+\mathrm{y}$. Arrows show the sex chromosomes. C. $-1: 3+$ Phase contrast. Two kinds of $M$ II plates: $10+X$ and $10+y$. Arrows show the sex chromosomes. D. $-\mathrm{KCl} 4 \mathrm{~h}+\mathrm{KS}+\mathrm{AgNOR}$. Two pairs of $\mathrm{T}$ I cells. Thin arrows show the nuclei where the argyrophilous $X$ chromosome is included. Thick arrow shows the same in an additional TI nucleus. A and C $2542 \mathrm{x} ; \mathrm{B} 1835 \mathrm{x}$; D $2255 \mathrm{x}$.

(Scarabaeidae) (23) and Lachnopus (Curculionidae) (27). Such cases were discussed by Smith and Virkki (15) to some extent because they are related with the "feed-in" of autosomes to the sex chromosome system, an evolutionary trend that has led to some of the most complicated sex chromosome systems known, in Blaps (Tenebrionidae). The first step is fusion of $\mathrm{X}$ or $\mathrm{y}$ with an autosome, whereby a free centric fragment emerges. Figure $4 \mathrm{~A}$ almost sustains this but figure $4, \mathrm{~B}$ negates it. The association is not permanent. Thus the translocation might have involved 
an exchange of pieces between the sex chromosome and the autosome, without formation of a loose fragment. By virtue of its segment derived from a sex chromosome, such an autosome has acquired a capacity to associate with the sex parachute, $\mathrm{Xy}_{\mathrm{p}}$. A somatogrammic order in the nucleus should facilitate both associations and translocations of closely-located chromosomes, and indeed one small bivalent tends to stay very close to the sex chromosomes in the bouquet stages of Diaprepes abbreviatus (fig. $3, \mathrm{~A}$ to $\mathrm{C}$ ).

This leaves open the derivation of the 1 or 2 tiny extra chromosomes (fig. 4). They resemble double minutes sometimes seen in vertebrate cells (2). If the above-mentioned translocation was complicated by gene amplification, such fragments may have originated simultaneously, thereafter accumulated or eliminated as dispensable supernumeraries.

Could genotype/karyotype manipulation somehow help in the control of vaquita?

Incorporation in the karyotype of recessive lethal genes, or semilethal gene systems like SIS (Semi-Incompatibility System) present in many North American Pissodes weevils $(15,25)$, would debilitate laboratoryreared demes. Although the techniques for transferring desirable genes from one organism to another are rapidly progressing (10), they offer greatest promise for improvement of domesticated and cultivated species that enjoy human protection. If such artifices had to compete with welladapted wild populations of their own species, they would likely become eliminated by selection. But if a meiotic drive system could be engaged to counteract the natural selection, desired genes might possibly be distributed even in a wild population (3). Because such a meiotic drive does not occur in vaquita, it should be constructed there. We tentatively suggest the following procedures based on existing cytological cases:

1. Inject a genetically inert but mitotically highly competent $B$ (supernumerary) chromosome into the vaquita karyotype. Such B chromosomes are present in the Coccinellid Chilocorus stigma, especially in its Canadian populations $(15,25)$.

2. Engineer the oocyte divisions in such a way that the B chromosome is always directed to the egg. Such a meiotic drive system would increase the $B$ frequency in the population and the individuals. Such systems occur naturally $(3,7,15$, pp. 69-71), suggesting that the meiotic spindle has latent potentialities for a preferred segregation of a given chromosome.

3. Insert mono- or oligophagy genes, and the genes controlling the meiotic drive, into the $\mathrm{B}$ chromosome $\left(\mathrm{B}-\mathrm{B}^{\prime}\right)$.

4. Release engineered beetles $\left(n \mathrm{~B}^{\prime}\right)$ to natural habitats.

This system might slowly withdraw the vaquita from most of its present host plants. Mono- or oligophagy genes should be preferred to reces- 
sive lethals, because the latter would eliminate homozygous $\left(B^{\prime} B^{\prime}\right)$ and hemizygous $\left(\mathrm{B}^{\prime}\right)$ conditions. Perhaps both systems could be combined by using autosomal lethals. Expression of even recessive mono- or oligophagy genes should start from hemizygous conditions $\left(\mathrm{B}^{\prime}, \mathrm{B}^{\prime} n \mathrm{~B}\right)$, and might increase (or turn lethal?) when the number of B's increases. An initial conflict needing additional engineering might arise from pressence of mono-, oligo- and polyphagy genes in one and the same genotype. Step 3 above could be shortened if the vaquita genotype would accept certain plant $\mathrm{B}$ chromosomes known to contain a meiotic drive gene (7).

Obviously, previous basic research in the genetics of mono-, oligoand polyphagy, and in the function of the achromatic spindle, would greatly benefit attempts at such bioengineering.

\section{LITERATURE CITED}

1. Cella, D. and A. Ferreira, 1983. Estudos cromossômicos de Cephalocoema sica (Orthoptera, Proscopiidae) através do emprego de técnica de coloraçäo diferencial (bandas $\mathrm{C}$ e impregnação argêntica). Naturalia 8: 169-76.

2. Cowell, J. K., 1988. Double minutes and homogeneously staining regions. Pp. 147-164 in Chromosomes and Chromatin II, K. W. Adolph, Ed, CRC Press, Florida.

3. Crow, J. F., 1988. The ultraselfish gene. Genetics 118: 389-91.

4. Figueroa, W. and J. Román, 1989. Parasitism of Neoaplectana carpocapsae, $N$. glaseri and $N$. bibionis in 3-4 months old larvae of Diaprepes abbreviatus (L.) (Coleoptera:Curculionidae). J. Agric. Univ. P. R. (Submitted).

5. Garcia de la Vega, C., C. López-Fernández, J. Gonsalves and J. S. Rufas, 1982. Cytogenetic studies on Chorthippus jucundus (Fish.) (Orthoptera). II. Heterochromatin variation and NOR localization. Cytobios 34: 7-14.

6. Hantula, J., A. Saura, J. Lokki and N. Virkki, 1987. Genic and color polymorphism in Puerto Rican phyllobiine weevils (Diaprepes abbreviatus (L.) and Compsus maricao Wolcott. J. Agric. Univ. P. R. 71: 391-97.

7. Jones, R. N. and H. Rees, 1982. B-chromosomes. Acad. Press, London.

8. Martorell, L. F., 1978. Annotated food plant catalog of the insects of Puerto Rico. Pbl. Agric. Exp. Stn., Univ. P. R., Rio Piedras.

9. Pathak, S. and F. F. B. Elder, 1980. Silver stained accessore structures on human sex chromosomes. Hum. Genet. 54: 171-75.

10. Perbal, B., 1984. A practical guide to molecular cloning. Wiley \& Sons, New York.

11. Rodríguez, N., J. Escudero and N. Virkki, Recombination indices of the Puerto Rican vaquita, Diaprepes abbreviatus (L.). (In preparation).

12. Rufas, J. S., J. Gonsalves, G. Giménez-Martín and P. Esponda, 1983. Localization and development of kinetochores, and chromatid core during meiosis in grasshoppers. Genetica 61: 233-35.

13. Rufas, J. S., J. Gonsalves, C. López-Fernández and H. Cardoso, 1983. Complete dependence between $\mathrm{Ag}-\mathrm{NOR}$ and $\mathrm{C}$-positive heterochromatin revealed by simultaneous Ag-NOR C-banding method. Cell Biol. Int. Rep. 7: 271-81.

14. Smith, S. G., 1965. Heterochromatin, colchicine, and karyotype. Chromosoma 16: 16265.

15. Smith, S. G. and N. Virkki, 1978. Animal Cytogenetics:Coleoptera. B. John, Ed. Gebr: Borntraeger, Stuttgart, West Germany.

16. Suomalainen, E., A. Saura and J. Lokki, 1987. Cytology and evolution in parthenogenesis. CRC Press, Florida. 
17. Takenouchi, Y., 1955. A chromosome survey in thirty species of the weevils (Curculionidae, Coleoptera). Jap. J. Zool. 11: 93-109.

18. - 1958. Further study of the chromosomes in curculionid weevils (Coleoptera). Jap. J. Genet. 33: 163-175.

19. - 1969. A study of the chromosomal dimorphism in Phyllobius longicornis Roelofs (Curculionidae, Coleoptera). Jap. J. Genet. 44: 93-96.

20. — 1979. The chromosomes of thirty-seven weevil species from Japan (Coleoptera:Curculionidae). Entomol. Gen. 6: 7-23.

21. — 1981. Chromosome numbers of Japanese weevils of Curculionidea (Coleoptera). II. Seibutsu-kyozai 16: 155-70.

22. Vidal, O. R. and R. O. Giacomozzi, 1978. Los cromosomas de la subfamilia Dynastinae (Coleoptera:Searabaeidae). II. Las bandas C en Enema pan (Fabr.). Physis C: 11319.

23. Virkki, N., 1967. Chromosome relationships in some North American scarabaeoid beetles, with special reference to Pleocoma and Trox. Can. J. Genet. Cytol. 9: 107-25.

24. — 1983. Banding of Oedionychina (Coleoptera:Alticinae) chromosomes: C- and Agbands. J. Agric. Univ. P. R. 67: 221-55.

25. - - 1984. Chromosomes in evolution of Coleoptera. Pp. 41-76 in Chromosomes in evolution of eukaryotic groups. II. A. K. Sharma and A. Sharma, Eds., CRC Press, Florida.

26. — and A. Denton, 1987. Silver staining of the elements of spermatogenesis in Oedionychina (Chrysomelidae:Alticinae). Hereditas 106: 37-49.

27. - C. Mazzella and A. Denton, Silver staining of the $X y_{p}$ sex bivalent of some weevils (Coleoptera:Curculionidae). (In preparation).

28. - C. Mazzella and A. Denton, Staining of substances adjacent to the $X y_{p}$ sex bivalent of some weevils of Puerto Rico. J. Agric. Univ. P. R. (Submitted).

29. Wolcott, G. N., 1948. The insects of Puerto Rico. Coleoptera. J. Agric. Univ. P. R. 32: $225-416$. 